\title{
Stratifying malaria receptivity in Bangladesh using archived rapid diagnostic tests
}

\author{
André Barembaye Sagna', Mohammad Golam Kibria², Shamsun Naher ${ }^{3}$, Shayla Islam³, M. M. Aktaruzzaman, \\ Mohammad Shafiul Alam² and Cristian Koepfli ${ }^{* *}$ (D)
}

\begin{abstract}
Background: Surveillance of low-density infections and of exposure to vectors is crucial to understand where malaria elimination might be feasible, and where the risk of outbreaks is high. Archived rapid diagnostic tests (RDTs), used by national malaria control and elimination programs for clinical diagnosis, present a valuable, yet rarely used resource for in-depth studies on malaria epidemiology.

Methods: 1022 RDTs from two sub-Districts in Bangladesh (Alikadam and Kamalganj) were screened by qPCR for low-density Plasmodium falciparum and Plasmodium vivax infections, and by ELISA for Anopheles salivary gland antibodies as a marker for exposure to vectors.

Results: Concordance between RDT and qPCR was moderate. qPCR detected 31/1022 infections compared to 36/1022 diagnosed by RDT. Exposure to Anopheles was significantly higher in Kamalganj despite low transmission, which could be explained by low bed net use.

Conclusions: Archived RDTs present a valuable source of antibodies for serological studies on exposure to vectors. In contrast, the benefit of screening archived RDTs to obtain a better estimate of clinical case numbers is moderate. Kamalganj could be prone to outbreaks.
\end{abstract}

Keywords: Rapid diagnostic test, Plasmodium falciparum, Plasmodium vivax, Malaria, Transmission, Surveillance, Salivary biomarker, Anopheles

\section{Background}

In many countries, scaled up malaria control has resulted in reduced morbidity and mortality. Between 2000 and 2015, malaria incidence worldwide fell by $37 \%$, malaria mortality by $60 \%$ [1], and an increasing number of countries now aim for malaria elimination. In recent years, however, progress in reducing transmission has stalled, with 228 million cases and 405,000 deaths reported in 2018 [2]. Rapid diagnosis and treatment of symptomatic individuals is critical, but parasite density in many individuals is below the limit of detection of microscopy or

\footnotetext{
*Correspondence: ckoepfli@nd.edu

1 Department of Biological Sciences, Eck Institute for Global Health, University of Notre Dame, Notre Dame, IN 46556-0369, USA

Full list of author information is available at the end of the article
}

rapid diagnostic test (RDT) of around 100 parasites/ $\mu \mathrm{L}$ blood. As a result, a large proportion of all infections among febrile individuals escape diagnosis $[3,4]$. This limitation also challenges surveillance, that relies on accurate case numbers and prevalence estimates.

In pre-elimination settings, surveillance is crucial to monitor the impact of control interventions and adapt strategies as needed. As alternative to case number routinely reported by health centres, molecular screening can be applied to screen for low-density infections, either among febrile patients, or among the general population to identify asymptomatic infections. Ideally, such screening is accompanied by entomological surveys to measure vector density and composition.

Molecular surveillance in malaria elimination settings across large geographical scales is challenging. Intensive

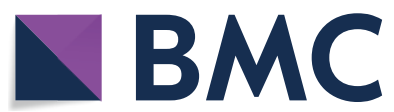

(c) The Author(s) 2020. This article is licensed under a Creative Commons Attribution 4.0 International License, which permits use, sharing, adaptation, distribution and reproduction in any medium or format, as long as you give appropriate credit to the original author(s) and the source, provide a link to the Creative Commons licence, and indicate if changes were made. The images or other third party material in this article are included in the article's Creative Commons licence, unless indicated otherwise in a credit line to the material. If material is not included in the article's Creative Commons licence and your intended use is not permitted by statutory regulation or exceeds the permitted use, you will need to obtain permission directly from the copyright holder. To view a copy of this licence, visit http://creativeco mmons.org/licenses/by/4.0/. The Creative Commons Public Domain Dedication waiver (http://creativecommons.org/publicdomain/ zero/1.0/) applies to the data made available in this article, unless otherwise stated in a credit line to the data. 
sampling activities are required to obtain sufficient specimens to identify risk factors and determine spatial heterogeneity [5]. As an alternative, specimens routinely collected by control and elimination programmes might be used. In the past two decades, RDTs have become a crucial tool for malaria diagnosis, with over 300 million tests used each year [6]. RDTs are lateral-flow devices that detect parasite proteins in a droplet of blood of approximately $5 \mu \mathrm{L}$ by immunohistochemistry. Numerous studies have shown that RDTs which have been used by health systems to screen febrile cases could be a useful source of parasite DNA for molecular studies [7-10], and for antibodies for serological surveys to estimate past exposure to malaria parasites [11].

As an alternative to entomological surveys, exposure to Anopheles vector bites can be assessed by Anopheles biting biomarkers [12]. During blood uptake, the Anopheles mosquito injects saliva containing immunogens into the host. Proteomic studies lead to the identification of small salivary proteins specific to Anopheles species. The human IgG responses to the gSG6 protein and the gSG6-P1 peptide were validated as serological indicators of exposure to Anopheles gambiae, Anopheles arabiensis and Anopheles funestus [13-15]. The antibody response to Anopheles saliva has been showed to gradually increase with increasing intensity of exposure to $A n$. gambiae sensu lato (s.l.) bites, as assessed by conventional entomological methods [16]. A drop in the anti-saliva IgG response to gSG6-P1 has been observed in children from Angola within a short period of time (6 weeks) after the interruption of exposure by bed net use [17]. The biomarker has been used to accurately evaluate the effectiveness of interventions and changes in transmission intensity in different sites in Africa and Asia [18-22], and seasonal fluctuations of specific IgG antibody levels according to exposure were found [19].

In Bangladesh Plasmodium falciparum and Plasmodium vivax are endemic along the north-eastern and south-eastern borders. In recent years, a significant decrease of malaria cases and deaths was achieved, with only 10,523 confirmed cases in 2018 compared to 39,719 cases in 2015 (NMEP MIS report). Transmission within Bangladesh is heterogenous. Most cases are reported from the three districts collectively known as Chittagong Hill Tract (CHT) in the south-east of the country [23]. No studies are available that applied PCR screening, and thus the extent of low-density infections is not known.

Each year, over 300,000 RDTs are used by the Bangladesh Malaria Elimination Program (NMEP) to screen febrile patients. qPCR screening was applied to 1022 archived RDTs from two Upazilas (sub-districts) to estimate the proportion of infections missed by routine diagnosis. For the first time, RDTs were used to study heterogeneity in exposure to Anopheles mosquitoes using an antibody-based salivary biomarker.

\section{Methods \\ Field specimens}

Archived RDTs and routine demographic data collected during diagnosis were obtained from the NMEP from 2 Upazilas in Bangladesh: Alikadam (Bandarban District, $\mathrm{n}=522$ RDTs, highest transmission in Bangladesh), and Kamalganj (Moulvibazar District, $\mathrm{n}=500$ RDTs, low transmission) [23, 24]. In Bangladesh, malaria occurs seasonally with the majority of malaria infections in the rainy season from May to October [25]. NMEP workers screen all febrile patients by RDT, and record the result, and data on age, gender, and bed net use using a unique ID, which is also written on the RDT. For the present study, the RDT was matched to the results from the NMEP database (i.e. the RDT result at the time of diagnosis was recorded). The RDTs for this study had been used for diagnosis in August-December 2018 and been stored at ambient temperature until processed in October 2019.

\section{DNA extraction and qPCR}

For initial testing, RDTs were prepared with whole blood spiked with cultured $P$. falciparum at densities of 20,000 and 10,000 parasites $/ \mu \mathrm{L}$. After 10 days of storage at $4{ }^{\circ} \mathrm{C}$, the RDT cassettes were opened, the entire RDT strip was removed, and fragments of the following components were sampled: sample pad and conjugate pad, nitrocellulose strip 1 (between the conjugate pad and the 1st test band), nitrocellulose strip 2 (between the two test bands), nitrocellulose strip 3 (between the 2nd test band and the filter paper), and filter paper. DNA was extracted with the NucleoMag whole blood kit (Macherey-Nagel) and screened by qPCR [26]. Plasmodium falciparum DNA was detected in almost all regions of the RDT, with the highest concentration DNA found in the first half of the RDT strip between the sample pad and the first test band. Thus, this part was used for screening of archived RDTs.

DNA was eluted in $25 \mu \mathrm{L}$ volume, and $4 \mu \mathrm{L}$ was used for screening for $P$. falciparum using the varATS assay [26] and for $P$. vivax using the cox 1 assay [27]. Both assays target multiple gene copies per parasite.

\section{Indirect enzyme-linked immunosorbent assay from RDTs}

For antibody elution, the second half of the RDT strip was cut into small pieces, placed in $1.5 \mathrm{~mL}$ microcentrifuge tubes, and immersed in $250 \mu \mathrm{l}$ PBS supplemented with $0.05 \%(\mathrm{v} / \mathrm{v})$ Tween-20 (VWR, USA) (PBS/T). RDT eluates were equivalent to a $1 / 100$ dilution of whole blood or $1 / 200$ of serum (assuming a haematocrit of approximately $50 \%$ ). Tubes were incubated overnight at 
$4{ }^{\circ} \mathrm{C}$, after which RDT eluates were separated from solid RDT components and stored at $-20^{\circ} \mathrm{C}$ until assayed.

ELISA conditions were standardized as described elsewhere [28]. Testing of serial dilutions of the eluate (1:10, 1:20 and 1:40 in PBS/T) showed optimal performance of the ELISA using a 1:10 dilution.

Nunc-Maxisorp 96-well plates were coated with 100 $\mu \mathrm{L} /$ well of gSG6-P1 peptide $(2 \mu \mathrm{g} / \mathrm{mL})$ diluted in $1 \times \mathrm{PBS}$. Plates were incubated at $37{ }^{\circ} \mathrm{C}$ for $2: 30 \mathrm{~h}$ and blocked with $3 \times 300 \mu \mathrm{L}$ of SuperBlock (TBS) Blocking Buffer. 100 $\mu \mathrm{L}$ of 1:10 diluted sample was added to each well. Plates were incubated overnight at $4{ }^{\circ} \mathrm{C}$, then washed three times and incubated $1: 30 \mathrm{~h}$ at $37^{\circ} \mathrm{C}$ with $100 \mu \mathrm{L} /$ well of a 1/500 dilution of mouse monoclonal anti-human IgG conjugated with biotin (BD Pharmingen). Peroxidase conjugated extravidine (GE Healthcare Life Sciences) was added at a $1 / 1000$ concentration and incubated $1 \mathrm{~h}$ at $37{ }^{\circ} \mathrm{C}$. After four final washes, colorimetric development was carried out using ABTS (2.2-azino-bis (3 ethylbenzthiazoline 6-sulfonic acid) diammonium (Sigma) in $50 \mathrm{mM}$ citrate buffer $\left(\mathrm{pH}=4\right.$, containing $0.003 \% \mathrm{H}_{2} \mathrm{O}_{2}$ ), and absorbance (OD) was measured at $405 \mathrm{~nm}$. All samples were tested in duplicate. Each microplate contained in duplicate: positive control, negative control, and blank wells. The positive control was a pool of dried blood spots of people with recent travel to a malaria endemic country, and their result was always above the cut-off for positivity. The negative control was a sample of people from US $(n=2)$ with no exposure to malaria vectors.

OD normalization and plate-to-plate variation were performed as described elsewhere [29]. Briefly, antibody levels were expressed as the $\triangle O D$ value: $\Delta \mathrm{OD}=\mathrm{ODx}-\mathrm{ODb}$, where ODx represents the mean of the technical replicates of each RDT, and ODb the mean of the blank wells. Positive controls of each plate were averaged and divided by the average of the ODx of the positive control for each plate to obtain a normalization factor. Each plate normalization factor was multiplied by the plate sample $\Delta \mathrm{OD}$ to obtain normalized $\Delta \mathrm{ODs}$ that were used in statistical analyses. The mean $\triangle \mathrm{OD}$ of negative US controls plus 3 standard deviations (SD) was used to determine cut-off value for responsiveness to the gSG6-P1 peptide. All serological data was analysed qualitatively, i.e. defining individuals as positive or negative based on a cut-off, and quantitatively, i.e. as median of all values (including data below the cut-off). Results are thus reported as seroprevalence, and as median antibody titres.

\section{Statistical analysis}

All data from questionnaires and forms were entered into a Microsoft Access database and statistical analyses were conducted using Graph Prism version 5.05 (Graph Pad
Software Inc.). Age, gender, bed net use, and upazila were analysed as risk factors for infection and exposure. The Chi square test was used for the comparison of number of positive samples between sites and age groups. After checking the normality distribution using KolmogorovSmirnov and Shapiro-Wilk tests, the non-parametric Mann-Whitney test was used to compare medians of specific IgG Ab levels between two independent groups. The non-parametric Kruskal-Wallis test was used for the comparison of more than two groups. Significance was assigned at $\mathrm{p}<0.05$.

Analysis by age-groups were considered using two groups: under 18 years-old and 18 years and older owing to the low number of infections recorded in smaller age-groups.

\section{Results}

\section{Infection status}

Table 1 describes the characteristics of the study population. The prevalence of $P$. falciparum and $P$. vivax combined was $3.52 \%(36 / 1022)$ by RDT and 3.3\% (31/1022) by qPCR screening of archived RDTs. The majority of infections by RDT $(91.7 \%, 33 / 36)$ and qPCR $(90.3 \%, 28 / 31)$ were $P$. falciparum; the remaining three were $P$. vivax. All positive RDTs were from Alikadam. RDT positivity was comparable between individuals aged 18 years and older $(3.6 \%, 25 / 683)$ and those younger $(3.2 \%, 11 / 339 ; \mathrm{p}=0.7)$.

Concordance between RDT and qPCR was low for $P$. falciparum. Among the 33 positive RDTs, only 20 were positive by $\mathrm{qPCR}$ ( $\geq 1$ gene copy/ $\mu \mathrm{L}$ eluted DNA). On the other hand, qPCR detected $P$. falciparum DNA from 11 negative archived RDTs. While all RDTs from Kamalganj were negative, qPCR diagnosed 1 low-density $P$. falciparum infection (3.9 copies/ $\mu$ L eluted DNA).

Eight out of eleven RDT-negative/qPCR-positive tests were from adults aged 18 years and older. As the majority of RDTs were from adults, the prevalence of sub-patent infection did not differ between age groups (8/658 in individuals aged 18 years and older, 3/325 in younger,

\section{Table 1 Descriptive statistics of participants by study site}

\begin{tabular}{lll}
\hline Characteristics & Alikadam (n= 522) & Kamalganj (n= 500) \\
\hline Age, years, median (range) & $22(0.5-70)$ & $27(2.5-75)$ \\
Female gender & $46 \%(240 / 522)$ & $49.8 \%(249 / 500)$ \\
LLIN use & $98.1 \%(469 / 478)$ & $26.4 \%(132 / 500)$ \\
RDT positivity ${ }^{a}$ & $6.9 \%(36 / 522)$ & $0.0 \%(0 / 500)$ \\
qPCR positivity $^{a}$ & $5.7 \%(30 / 522)$ & $0.2 \%(1 / 500)$ \\
Immune responders $_{\text {Antibody titres, median }}$ & $9.9 \%(52 / 522)$ & $7 \%(35 / 500)$ \\
(range) & $0.035(0.0-2.1)$ & $0.062(0.0-0.70)$ \\
\hline
\end{tabular}

a $P$. falciparum and $P$. vivax combined. Result from time point of diagnostic testing in the field 
$\mathrm{p}=0.671)$. Likewise, the proportion of sub-patent infections among all infections did not differ $(8 / 31$ in individuals aged 18 years and older, $3 / 31$ in younger, $\mathrm{p}=0.183$ ). The mean $P$. falciparum density of RDT-negative/qPCRpositive tests (12.9 copies/ $\mu \mathrm{L}$ eluted DNA, 95\% Confidence Interval (CI 95) 9.4-35.3) was significantly lower than of RDT-positive tests (154.6 copies/ $\mu \mathrm{L}$ eluted DNA, CI 95 2.1-311.2; $\mathrm{p}<0.0001)$.

Results were in full concordance for $P$. vivax. All 3 positive RDTs were confirmed by qPCR and no additional infections were detected.

\section{Exposure to Anopheles}

The sero-prevalence of specific IgG to Anopheles gSG6P1 salivary peptide did not vary significantly between Alikadam $(9.9 \%, 52 / 522)$ and Kamalganj $(7.0 \%, 35 / 500$, $\mathrm{p}=0.08$, Table 1, Additional file 1: S1). In contrast, the median titres significantly varied between the two study sites and was higher in Kamalganj, the low transmission area ( $\mathrm{p}<0.0001$; Fig. 1a). This result could be explained by lower bed net use in Kamalganj. The rate of mosquito net use 15 days prior the RDT collection was significantly higher in Alikadam (98.1\%, 469/478) compared to Kamalganj $(26.4 \%, 132 / 500, \mathrm{p}<0.0001$, Table 1$)$. People who declared having slept under a LLIN (LongLasting Insecticidal Net) 15 days prior the RDT collection had significantly lower anti-gSG6-P1 IgG levels compared to those who did not (all $p<0.05$; Fig. 1b). In Kamalganj, gSG6-P1 antibody titres remained constant from August to October, and then gradually increased until December ( $<<0.0001$; Fig. 1c). Titres did not significantly vary from October to December in Alikadam $(\mathrm{p}=0.421$; Fig. $1 \mathrm{c})$. Median antibody titres did not differ across age groups $(p=0.053$; Fig. $1 d)$. a

Sites

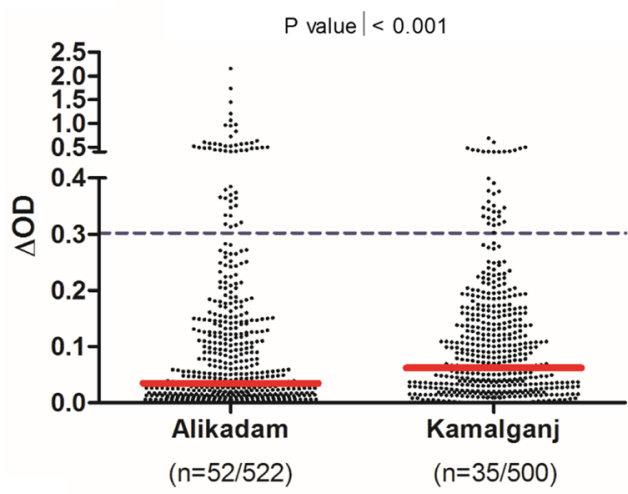

C

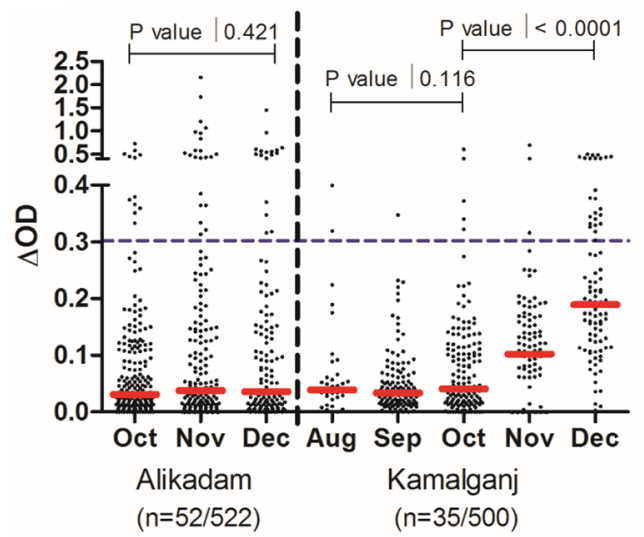

b

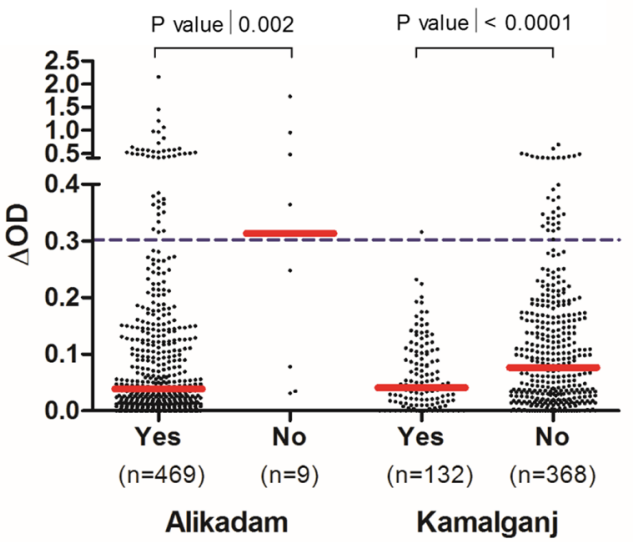

d

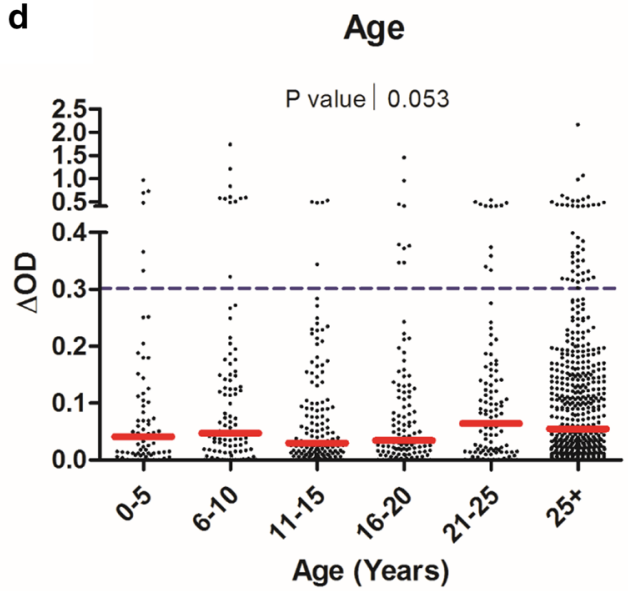

Fig. 1 Specific lgG levels to the Anopheles gSG6-P1 salivary peptide in Alikadam and Kamalganj, Bangladesh. Black dots indicate individual lgG responses, and bars represent median values in each group. Dotted lines represent the cut-off of a specific Ab response $(\triangle O D>0.300)$. Statistically significant differences between the two (nonparametric Mann-Whitney test) and three or more groups (nonparametric Kruskal-Wallis test) are indicated 
Considering only individuals with antibody titres above the threshold for positivity $(\mathrm{n}=87)$, the median antibody titre was higher in Alikadam $(p=0.0002$, Additional file 2: Fig. S2A). This indicates that those that are exposed to Anopheles in Alikadam experience higher exposure than exposed individuals in Kamalganj. Not using a bed net remained a significant risk factor for exposure to Anopheles ( $\mathrm{p}=0.0012$, Additional file 2: Fig. S2B). Differences across seasons were not significant $(p=0.128$, Additional file 2: Fig. S2C), while medians of antibody titres decreased with increasing age $(\mathrm{p}=0.0115$, Additional file 2: Fig. S2D).

\section{Discussion}

Molecular screening for low density infections and entomological surveys on vector exposure can greatly enhance our understanding of malaria transmission. Sample collection for such surveys spanning large geographical areas is often logistically difficult. This study showed that archived RDTs can present a valuable additional source of specimens for malaria surveillance. While few additional infections were detected, pronounced differences in vector exposure were observed between seasons, and higher exposure was shown in individuals not using a bed net even in a low transmission setting.

As observed in other studies [8], screening of archived RDTs by qPCR yielded few additional infections. In contrast, comparing RDT for diagnosis of febrile patients to qPCR using properly stored blood samples, RDT sensitivity is often below 50\% [4]. The low volume of blood applied to the RDT and further dilution during DNA extraction, combined with long storage at ambient temperature resulted in markedly reduced sensitivity by qPCR. DNA degradation can also explain the high number of positive RDTs that were negative by $\mathrm{qPCR}$, along with other factors such as persistence of the antigen after parasite clearance or cross-reactivity of the antibody bound to the RDT with non-Plasmodium antigens [30]. In summary, the benefit of qPCR-screening of archived RDTs to obtain a better picture of case numbers was moderate.

Studying vector density as a surrogate marker for the risk of malaria re-emergence is costly [5]. Measuring exposure to Anopheles vectors through salivary gland antibody biomarkers presents a cost-efficient alternative, in particular when archived RDTs are analysed.

Exposure to Anopheles mosquitoes was higher in Kamalganj where transmission is low, compared to Alikadam, a high transmission area. This result can be explained by much lower bed net use. Only a quarter of patients in Kamalganj reported sleeping under a bed net, compared to nearly all in Alikadam. Antibody titres in individuals from Kamalganj using a bed net did not differ from those in Alikadam. Overall, the results indicate frequent exposure to vectors in Kamalganj despite a low number of clinical malaria cases. Detailed entomological surveys will be required to accurately quantify vector density and behavior, such as the proportion of indoor biting that could be prevented by higher bed net use. The exposure to Anopheles increased significantly from October to December in Kamalganj, likely representing seasonal changes in transmission potential [31]. Given the high human-vector contact in Kamalganj in November and December, this site could be prone to outbreaks. The risk is particularly high as $h r p 2$ deletions have been reported from this area, hampering diagnosis by RDT [32].

The seropositivity values determined in this study cannot be compared directly to values measured in population surveys elsewhere [18-21]. First, samples included only febrile patients. Their exposure might not be representative for the entire population. Second, the volume of blood on the RDT is minimal, and storage at ambient temperature resulted in degradation of antibodies. This was evident by low median IgG levels of anti-gSG6-P1. The technical error of the measurements was probably increased because of the storage conditions. Analysing a larger blood volume stored in a freezer would likely yield higher antibody titres. Future studies comparing RDT and whole blood stored under different conditions will be necessary to quantify the impact of storage. Nevertheless, as storage conditions were the same for all RDTs, results obtained in this study from different sites or across age groups can be compared among each other.

\section{Conclusions}

This study demonstrated the usefulness of archived RDTs for quantifying human-vector contact, and in general for serological surveys in elimination settings. While the low number of infections in Kamalganj precluded analysis of the benefits of bed net usage, the serological data clearly showed that exposure to vectors is high among those not using bed nets. The presence of a sub-patent $P$. falciparum infection detected by qPCR, and sporadic reports of clinical cases highlight the potential for outbreaks. Thus, malaria prevention interventions need to be maintained in low transmission settings in Bangladesh.

\section{Supplementary information}

Supplementary information accompanies this paper at https://doi. org/10.1186/s12936-020-03418-y.

Additional file 1. Serological database

Additional file 2: Figure S2. Specific lgG levels to the Anopheles gSG6-P1 salivary peptide for seropositive individuals only $(n=87)$. 


\section{Acknowledgements}

We are grateful to NMEP and BRAC, the lead NGO partner for malaria elimination in Bangladesh, for providing archived RDTs and demographical data. icddr,b is grateful to the Government of Bangladesh, Canada, Sweden, and the UK for providing core/unrestricted support.

\section{Authors' contributions}

CK and MSA conceived the study and acquired the funding, MGK, SN, SI, and MMA obtained the RDTs and recorded the demographic data, ABS and MGK conducted the lab work, ABS, MSA and CK analysed the data and wrote the manuscript. All authors read and approved the final manuscript.

\section{Funding statement}

This project was supported, in part, by the Indiana Clinical and Translational Sciences Institute, funded, in part by Grant Number UL1TR002529 from the National Institutes of Health, National Center for Advancing Translational Sciences, Clinical and Translational Sciences Award; by NIH Grant R21Al137891, Notre Dame International, and by the Eck Institute for Global Health at the University of Notre Dame. The content is solely the responsibility of the authors and does not necessarily represent the official views of the National Institutes of Health.

\section{Availability of data and materials}

All data is available within the manuscript and in Additional file 1: S1.

\section{Ethics approval and consent to participate}

IRB approval was obtained from the University of Notre Dame Office of Research Compliance (approval number 19-04-5329).

\section{Consent for publication}

Not applicable.

\section{Competing interests}

The authors declare that they have no competing interests.

\section{Author details}

${ }^{1}$ Department of Biological Sciences, Eck Institute for Global Health, University of Notre Dame, Notre Dame, IN 46556-0369, USA. ${ }^{2}$ Infectious Diseases Division, International Centre for Diarrhoeal Disease Research Bangladesh (icddr, b), 68 Shaheed Tajuddin Ahmed Sarani, Mohakhali, Dhaka 1212, Bangladesh. ${ }^{3}$ Communicable Diseases Programme (Malaria), BRAC, BRAC Centre, 75 Mohakhali, Dhaka 1212, Bangladesh. ${ }^{4}$ National Malaria Elimination Program, Communicable Disease Control, Directorate General of Health Services, Dhaka, Bangladesh.

Received: 12 June 2020 Accepted: 15 September 2020

Published online: 23 September 2020

\section{References}

1. WHO. World Malaria Report 2015. Geneva: World Health Organization; 2015

2. WHO. World Malaria Report 2019. Geneva: World Health Organization; 2019

3. Challi S, Miecha H, Damtie D, Shumie G, Chali W, Hailu T, et al. The unmet need: low performance of laboratory professionals in malaria microscopy, Oromia Regional State, Ethiopia. Am J Trop Med Hyg. 2020;102:117-20.

4. Mwesigwa J, Slater H, Bradley J, Saidy B, Ceesay F, Whittaker C, et al. Field performance of the malaria highly sensitive rapid diagnostic test in a setting of varying malaria transmission. Malar J. 2019:18:288.

5. Tusting LS, Bousema T, Smith DL, Drakeley C. Measuring changes in Plasmodium falciparum transmission: precision, accuracy and costs of metrics. Adv Parasitol. 2014:84:151-208.

6. Rapid diagnostic tests www.who.int/malaria/areas/diagnosis/rapid_diagn ostic_tests/en/.

7. Morris U, Aydin-Schmidt B, Shakely D, Martensson A, Jornhagen L, Ali AS, et al. Rapid diagnostic tests for molecular surveillance of Plasmodium falciparum malaria-assessment of DNA extraction methods and field applicability. Malar J. 2013;12:106.
8. Guirou EA, Schindler T, Hosch S, Donfack OT, Yoboue CA, Kraehenbuehl S, et al. Molecular malaria surveillance using a novel protocol for extraction and analysis of nucleic acids retained on used rapid diagnostic tests. medRxiv. 2020

9. Veron V, Carme B. Recovery and use of Plasmodium DNA from malaria rapid diagnostic tests. Am J Trop Med Hyg. 2006;74:941-3.

10. Guiguemde KT, Dieye Y, Lo AC, Ndiaye M, Lam A, Manga IA, et al. Molecular detection and quantification of Plasmodium falciparum gametocytes carriage in used RDTs in malaria elimination settings in northern Senegal. Malar J. 2020;19:123.

11. Williams GS, Mweya C, Stewart L, Mtove G, Reyburn H, Cook J, et al. Immunophoretic rapid diagnostic tests as a source of immunoglobulins for estimating malaria sero-prevalence and transmission intensity. Malar J. 2009;8:168.

12. Poinsignon A, Cornelie S, Ba F, Boulanger D, Sow C, Rossignol M, et al. Human IgG response to a salivary peptide, gSG6-P1, as a new immunoepidemiological tool for evaluating low-level exposure to Anopheles bites. Malar J. 2009:8:198.

13. Poinsignon A, Samb B, Doucoure S, Drame PM, Sarr JB, Sow C, et al. First attempt to validate the gSG6-P1 salivary peptide as an immuno-epidemiological tool for evaluating human exposure to Anopheles funestus bites. Trop Med Int Health. 2010;5:1198-203.

14. Rizzo C, Ronca R, Fiorentino G, Verra F, Mangano V, Poinsignon A, et al. Humoral response to the Anopheles gambiae salivary protein gSG6: a serological indicator of exposure to Afrotropical malaria vectors. PLoS ONE. 2011;6:e17980.

15. Badu K, Siangla J, Larbi J, Lawson BW, Afrane Y, Ong'echa J, et al. Variation in exposure to Anopheles gambiae salivary gland peptide (gSG6-P1) across different malaria transmission settings in the western Kenya highlands. Malar J. 2012;11:318.

16. Remoue F, Cisse B, Ba FT, Sokhna C, Herve JP, Boulanger D, et al. Evaluation of the antibody response to Anopheles salivary antigens as a potential marker of risk of malaria. Trans R Soc Trop Med Hyg. 2006;100:363-70.

17. Drame PM, Poinsignon A, Besnard P, Cornelie S, Le Mire J, Toto JC, et al. Human antibody responses to the Anopheles salivary gSG6-P1 peptide: a novel tool for evaluating the efficacy of ITNs in malaria vector control. PLOS ONE. 2010;5:e15596.

18. Drame PM, Diallo A, Poinsignon A, Boussari O, Dos Santos S, Machault V et al. Evaluation of the effectiveness of malaria vector control measures in urban settings of Dakar by a specific anopheles salivary biomarker. PLoS ONE. 2013;8:e66354.

19. Sagna AB, Sarr JB, Gaayeb L, Drame PM, Ndiath MO, Senghor S, et al. gSG6-P1 salivary biomarker discriminates micro-geographical heterogeneity of human exposure to Anopheles bites in low and seasonal malaria areas. Parasit Vectors. 2013;6:68.

20. Noukpo MH, Damien GB, Elanga-N'Dille E, Sagna AB, Drame PM, Chaffa E, et al. Operational assessment of long-lasting insecticidal nets by using an Anopheles salivary biomarker of human-vector contact. Am J Trop Med Hyg. 2016;95:1376-82.

21. Traore DF, Sagna AB, Adja AM, Zoh DD, Lingue KN, Coulibaly l, et al. Evaluation of malaria urban risk using an immuno-epidemiological biomarker of human exposure to Anopheles bites. Am J Trop Med Hyg. 2018;98:1353-9.

22. Ya-Umphan P, Cerqueira D, Parker DM, Cottrell G, Poinsignon A, Remoue $F$, et al. Use of an Anopheles salivary biomarker to assess malaria transmission risk along the Thailand-Myanmar border. J Infect Dis. 2017:215:396-404.

23. Noe A, Zaman SI, Rahman M, Saha AK, Aktaruzzaman MM, Maude RJ. Mapping the stability of malaria hotspots in Bangladesh from 2013 to 2016. Malar J. 2018;17:259.

24. Reid HL, Haque U, Roy S, Islam N, Clements AC. Characterizing the spatial and temporal variation of malaria incidence in Bangladesh, 2007. Malar J. 2012;11:170.

25. Maude RJ, Hasan MU, Hossain MA, Sayeed AA, Kanti Paul S, Rahman W, et al. Temporal trends in severe malaria in Chittagong, Bangladesh. Malar J. 2012;11:323.

26. Hofmann N, Mwingira F, Shekalaghe S, Robinson LJ, Mueller I, Felger I. Ultra-sensitive detection of Plasmodium falciparum by amplification of multi-copy subtelomeric targets. PLoS Med. 2015;12:e1001788. 
27. Gruenberg M, Moniz CA, Hofmann NE, Wampfler R, Koepfli C, Mueller I, et al. Plasmodium vivax molecular diagnostics in community surveys: pitfalls and solutions. Malar J. 2018;17:55.

28. Sagna AB, Kassie D, Couvray A, Adja AM, Hermann E, Riveau G, et al. Spatial assessment of contact between humans and Anopheles and Aedes mosquitoes in a medium-sized African urban setting, using salivary antibody-based biomarkers. J Infect Dis. 2019;220:1199-208.

29. Londono-Renteria B, Drame PM, Weitzel T, Rosas R, Gripping C, Cardenas JC, et al. An gambiae gSG6-P1 evaluation as a proxy for human-vector contact in the Americas: a pilot study. Parasit Vectors. 2015;8:533.

30. Gatton ML, Ciketic S, Barnwell JW, Cheng Q, Chiodini PL, Incardona S, et al. An assessment of false positive rates for malaria rapid diagnostic tests caused by non-Plasmodium infectious agents and immunological factors. PLoS ONE. 2018;13:e0197395.
31. Al-Amin HM, Elahi R, Mohon AN, Kafi MA, Chakma S, Lord JS, et al. Role of underappreciated vectors in malaria transmission in an endemic region of Bangladesh-India border. Parasit Vectors. 2015;8:195.

32. Nima MK, Hougard T, Hossain ME, Kibria MG, Mohon AN, Johora FT, et al. A case of Plasmodium falciparum hrp2 and hrp3 gene mutation in Bangladesh. Am J Trop Med Hyg. 2017;97:1155-8.

\section{Publisher's Note}

Springer Nature remains neutral with regard to jurisdictional claims in published maps and institutional affiliations.
Ready to submit your research? Choose BMC and benefit from:

- fast, convenient online submission

- thorough peer review by experienced researchers in your field

- rapid publication on acceptance

- support for research data, including large and complex data types

- gold Open Access which fosters wider collaboration and increased citations

- maximum visibility for your research: over 100M website views per year

At BMC, research is always in progress.

Learn more biomedcentral.com/submissions 